\title{
Effect of Business Operation Period on the Relationship Between Knowledge Management Applications and Ship Performance
}

\author{
(1) Murat Yorulmaz ${ }^{1}$, (1) Ahmet Karabacak ${ }^{2}$ \\ ${ }^{1}$ Kocaeli University Maritime Faculty, Department of Maritime Business Administration, Kocaeli, Turkey \\ ${ }^{2}$ Directorate General of Coastal Safety, İzmir, Turkey
}

\begin{abstract}
This study aims to examine the effect of knowledge management (KM) on the cargo performance (CP) and navigational performance (NP) of ships and to determine whether the business operation period of the firm has a moderating effect in this relationship by means of KM applications used in businesses operating in international markets. This work also investigates the impact of the business operation period on the ship's CP and NP. Data were obtained by administering a questionnaire to 451 employees who work in a total of 67 ship businesses operating in Turkey and analyzed using SPSS 22 Hayes (2019) Process macro (v3.4) and AMOS 22 programs. Findings indicated that the KM applied in ship businesses has a positive effect on both performances of ships, explaining about $17 \%$ and $13 \%$ of the change in their navigation performance and CP, respectively. This study concluded with suggestions to the managers of ship businesses on how to render their KM applications more efficiently and effectively.
\end{abstract}

\section{Keywords}

Knowledge management, Navigational performance, Cargo performance, Ship performance, Ship management, Maritime business

\section{Introduction}

Knowledge management (KM), which involves acquiring, transforming, and applying knowledge [1], requires a company-wide strategy that includes the knowledge available when and where it is needed, ensuring the availability from external and internal sources. This includes the process of continuously managing all kinds of knowledge and their implementation, monitoring, and evaluation [2]. KM seeks to ensure that an organization gains awareness of the knowledge it has, either on an individual basis or a collective basis, and transforms itself to use the knowledge it possesses or can acquire most effectively and efficiently. Thus, this makes it a pivotal factor in making organizations competitively advantageous in volatile markets [3]. For an organization to be able to adapt to changing conditions, it must acquire knowledge from different sources and transform them into an application process to use the acquired knowledge in line with its goals and activities [4]. In the narrowest sense, KM, involving various activities, consists of five main processes: creating, storing, possessing, transferring, and implementing knowledge [5]. KM applications, the most important process of KM, aim to combine corporate memories in the form of corporate intranets to improve the knowledge of the organization and consequently enhance the quality of the service provided to customers and users [6]. This facilitates observing and improving the value, benefit, and contribution of the acquired knowledge. Maritime transportation, carrying more than $80 \%$ of the global trade volume, continues to be the backbone of the global trade and manufacturing supply chain. The world maritime transportation, which was 2,605 million tons in the 1970s, has reached 11,005 million tons as of the end of 2018 [7]. KM has increasing importance in maritime transportation, which offers large-scale services and has its own dynamics. Ports, maritime businesses, and

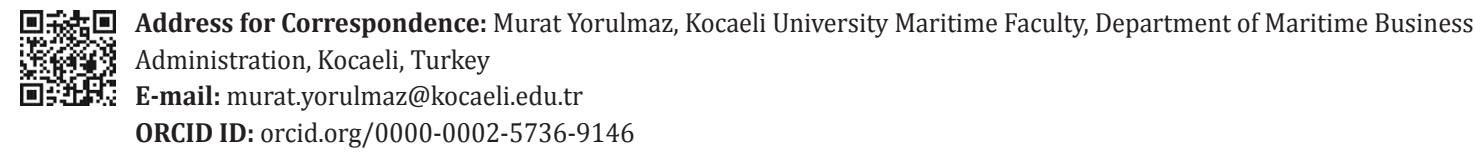


intermediary firms, which seemed independent from each other in the past, urge all stakeholders to work efficiently and effectively among each other to meet their needs with the integration of technology boosted by globalization. Therefore, the value and success of maritime businesses at the center of the logistics system depend on how well they react to the demands of their customers in the logistics system by correctly managing the flow of goods, services, and knowledge, making this a strategic issue for businesses [8]. KM applications both enhance the service quality of maritime transportation companies that control maritime transport, which is essential for commercial activities, and improve their performance by providing them with a competitive advantage. A study that was simultaneously performed in the production and service sector in three different countries indicated that KM applications increase the competitiveness and economic performance of companies [9]. Research conducted in different sectors revealed that it would allow for more efficient use of resources and consequently a more innovative and better performance [10]. Moreover, it also contributes to the organizational performance of the production, finance, and service sectors [11], enhances the organizational performance in software companies [12], supports the performance of nurses, and minimizes hospital expenses in the health sector [13].

Although many studies on the effect of KM applications on organizational performance are available, research in the maritime field is limited. This study is of great significance as it seeks to address a research gap in the literature and to evaluate ship performance (SP) based on a different method. This work aims to examine the relationship between KM applications in internationally operating shipping companies and the navigational and cargo performances (CPs) of ships and to reveal whether the activity period of the firm has a moderating effect in this relationship.

\section{Literature Review and Hypotheses}

\subsection{Knowledge Management}

Acquisitions resulting from the interaction of humans with concrete or abstract objects are called knowledge [14], and people have an unlimited ability to produce knowledge [15]. The knowledge produced through experiences can only be beneficial if it is used correctly in the interests of the individual and of the community. In addition to social and collaborative processes, knowledge is formed, shared, strengthened, enhanced, and justified through the cognitive processes of individuals [16]. Among the two basic types of knowledge (i.e., implicit knowledge and explicit knowledge) in organizations and individuals, the most valuable and remarkable type is the implicit knowledge, which is in the mind of the individual [17]. New knowledge is generated from existing knowledge by transforming it with the implicit and explicit knowledge of the organization or by developing the content [18]. The internalization process of knowledge, one of the most critical processes in the KM application, is the process of developing the knowledge that is explicit by integrating it with the implicit knowledge of the organization's employees and thus turning it back into implicit knowledge [19]. The internalization of knowledge is the process of integrating and synthesizing explicit knowledge through experience, and organizations must make it accessible to facilitate the internalization of knowledge among organization members to enhance the value of their knowledge [20]. The most pivotal factor in the development, dissemination, and benefit of knowledge is that knowledge becomes open, i.e., it is shared. Knowledge exchange among organizational staff members is an essential component in the KM process, but developments in modern information and communication technology eliminate and facilitate time and distance limits for such exchanges [21]. Knowledge shared among the most basic level employees in organizations is seen as an important strategic resource for organizations. Therefore, the proper management of this resource is critical to the corporate's success, which is related to the formation, sharing, and usage of knowledge within the organization [22]. Knowledge sharing is different than communication or knowledge distribution as it occurs between two parties, one of whom communicates knowledge either consciously or not, by acts, by speech, or in writing, etc., while the other should be able to perceive these expressions of knowledge and make sense of them [23]. In this context, healthy knowledge sharing is only possible when the shared knowledge is positioned and evaluated by stakeholders with the same perspective, something beyond knowledge transfer (KT). Knowledge acquired, internalized, and shared can only be beneficial if it is implemented and used. The application and use of knowledge refer to the process where knowledge is utilized in making decisions or policies [24]. For this reason, when a business fails to implement and utilize its sources of information efficiently and effectively, its abilities in creating, storing, and sharing these sources become useless and the KM process loses its significance.

\subsection{Performance}

Outside of any specific context, performance can be associated with the completion of a range of acts, from simple and mundane acts, momentary or short-term, to long-term and more detailed acts [25]. According to Dooren et al. [26], performance, which can be expressed as sustainable results that are conceptualized by considering the quality of actions and achievements, refers to the productive organization, 
or in other words, the process that includes the entire value chain from inputs over outputs to results. Therefore, in broader terms, performance can be described as being able to complete a pre-planned act within a specific time. However, it is possible to define organizational performance as the degree to which businesses achieve their goals [27]. Organizational performance assessed within the framework of the activities of organizations can be considered at different levels: the cost of producing a designated product using a product or the efficiency of performing a particular task [28]. For organizations that can be considered in two groups according to their purposes as financial and nonfinancial, organizational performance is entirely related to the structure of the organization and is about achieving the goals the organization defines within its own framework [29]. In this context, the definition of organizational performance, which does not offer a sound assessment method, may differ across different disciplines. The level of organizational performance depends on employee satisfaction, organizational commitment, motivation, and feelings of organizational citizenship, and individual factors [30]. Performances of ships, which have hierarchical structures just like an organization, are important for maritime businesses. The prediction of the navigational performance (NP) of ships is linked to the interaction of ships with the resistance they encounter during the voyage. Routes determined using the software designed for voyage optimization are intended to enhance NP. The optimum route is described as the route that has the least fuel consumption, taking into consideration the average ship's speed, sea conditions to be encountered, and the voyage period [31]. For a long time, performance has been assessed using relatively simple procedures. These procedures report the fuel consumption daily as well as the distance that a ship traveled within 24 hours in the "Noon Report," which includes the average speed observed and weather observations. Performance is a measure of the energy consumption in a particular state, namely speed, ship cargo condition, weather, and other factors (waves, shallow water, changes in seawater temperature, etc.), and will decrease over the life of the ship [32]. In merchant ships, which primarily seek to carry cargo, the SP depends on two main activities: navigational activities where processes related to route, maneuvering, direction, and position are performed to allow ships to move safely between specified ports, and operations involving balance, stress, loading, and unloading of the cargo shipped [33]. That said, one of the prominent factors that are influential in the performance of a ship is possibly the cargo operations that determine the draught, trim, and aerodynamic structure of the vessel. Another influential factor is the geographical area involving external factors that affect this structure such as currents, winds, and temperatures.
Through performance measurement systems, an organization can track the progress it made toward its objectives and thereby understand its current status, the key issues that need to be addressed, and the available options [34]. Therefore, measuring, analyzing, and interpreting the performance of a business with the right methods is as important and necessary as the performance of the business. Studies on the measurement of the ship's performance mainly focus on the energy efficiency, bunker consumption, propeller, and engine performance obtained by quantitative methods [35-41]. Unlike these studies, the performance of five ships of Turkish maritime lines, operating in the dry cargo market in Turkey, was measured using the effectiveness and performance measurement criteria (key performance indicators, KPI), which were developed by the MARINTEK Institute. It was concluded that the environmental and healthsafety-related navigational and operational performances of maritime lines are sufficient, but the technical performance is poor [42]. Another study conducted with four different ships employed in a short-distance freight transport of four shipping companies revealed that ships of companies that use outsourcing in their management perform better according to KPI standards [43]. This present study, based on the definition of performance, seeks to evaluate the cargo and NPs of ships, which is a process extending from inputs to outputs and results, by drawing on the perceptions of the employees.

\subsection{Relationship Between KM and Performance}

Studies on KM and performance in various fields are available in the literature. A study with 314 executives in the trade and service sector found that KM processes had a positive and significant effect on innovation performance, although knowledge hoarding harmed this performance [44]. The integrative relationship between flexibility and organizational performance was examined in 838 companies in the industry and service sector in Spain with 15 or more employees, revealing that KM had a positive effect on organizational performance [45]. In Bahrain, a study conducted with 119 human resources managers and general managers in companies operating in the service sector, including sectors such as health, accounting, transportation, retail, hotel, educational institutions, and consultancy services, determined that the KM process had a positive correlation with the organizational performance [46]. Another study performed with 151 people on the impact of the KM process (collecting, transforming, using, and protecting knowledge) on the organizational performance in the finance sector indicated a positive relationship only between using and protecting knowledge and organizational performance [47]. Another study was carried out in 270 public businesses across the United 
Arab Emirates, revealing that KM processes have varying impacts on performance. In other words, the KM process has its strongest effect on innovative performance, followed by concepts of quality and operational performance [48]. Research with post-graduate students at the University of Delhi, India, found that the KM system has a direct and significant impact on the student's performance [49]. In addition, a study with senior executives of 69 companies that provide ocean freight services registered in the Korea International Freight Forwarding Association, determined that KM in logistic companies enhanced the organizational performance. It was further revealed that companies carrying out maritime transportation obtain information in cooperation with companies both within internal and external sources and manage information effectively to improve their corporate performance. Results show that the information of maritime companies is a decisive resource to increase their logistics value and innovative capability [50]. Another study with 83 managers registered in the National Maritime Agents and Companies Association, operating internationally in the regular line transportation in Taiwan determined that KM is positively associated with innovation and that there is a positive relationship between the KM culture and innovation, financial, and customer service performances of organizations. It also revealed that information technology does not directly support all kinds of corporate performance, and the organizational structure and KM culture are found to be related to corporate performance such as innovation, finance, and customer service [51]. The literature review showed that KM applications have an important and positive effect on performance. Hence, hypothesis 1 and hypothesis 2 were proposed.

Hypothesis 1: KM applications in ship businesses positively affect navigation performance.

Hypothesis 2: KM applications in ship businesses positively affect CP.

Some studies on KM and performance tested and assessed different concepts that have a moderating role between or are believed to have a directrole on KM and performance. The effect of the demographic characteristics and KM providers of construction companies on the firm performance was investigated in a study with 105 large-scale construction companies operating in the construction industry in Turkey, 54 of which are members of the Contractors' Association. Statistically evaluated findings showed that there was a positive and significant relationship between the technological KM and structural KM providers and the performance of construction companies, but there was no positive and significant relationship between the cultural KM provider and the performance of the construction company.
A two-step hierarchical multiple regression analysis revealed that the firm's age and size cannot statistically affect the firm's performance and that they do not have a statistically significant relationship with the organization's performance [52]. Face-to-face surveys with managers working in the accounting department of 53 small and midsize enterprises demonstrated that there is a statistically significant difference between the level at which they use the knowledge obtained from databases of other units in accounting-related tasks and the establishment year of the business and the number of employees in the business [53]. Based on these studies, hypothesis 3 and hypothesis 4 were proposed:

Hypothesis 3: The business operation period (BOP) has a moderating role in the effect of KM applications on the navigation performance in ship businesses.

Hypothesis 4: The BOP has a moderating role in the effect of KM applications on the CP in ship businesses.

Figure 1 shows the research model designed considering the hypotheses proposed above in light of the discussed information.

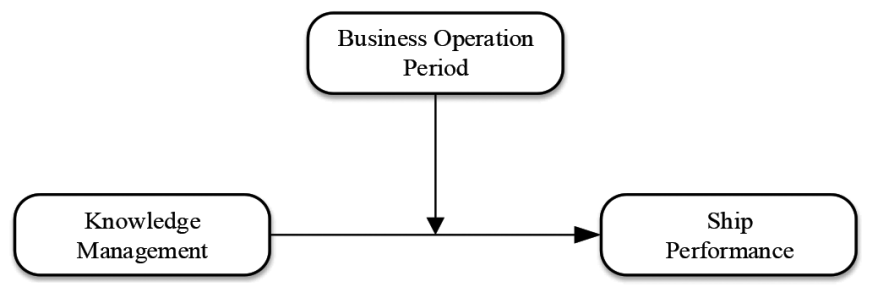

Figure 1. Research model

\section{Materials and Methods}

\subsection{Sampling and Data Collection}

Data were obtained using the questionnaire method to determine the effect of KM applications in ship operations on the NP and CP of ships and whether the operation period of the firm has a moderating role in this interaction. Questionnaires were applied face-to-face and through e-mail to the employees of 67 volunteer ship businesses in Turkey between September 2019 and March 2020. Data from 451 questionnaires that were filled in completely and correctly were used for the analysis.

Most of the participating ship management employees are male (365 participants, $80.9 \%$ ). Two hundred and six $(45.7 \%)$ of them are aged $35-45$ years, while $14(3.1 \%)$ are aged 20-25 years. Two hundred and ninety-four of the employees (65.2\%) are university graduates. Hundred and five employees $(23.3 \%)$ work in the technical department, 93 (20.6\%) work in the human resources department, and $67(14.9 \%)$ serve in the operation department. One hundred 
and thirty-five employees (29.9\%) are managers including those of the lower level, middle level, and top level. Of the employees, 109 (24.2\%) have 4-7 years of work experience, whereas $60(13.3 \%)$ have 3 years or less of work experience. Also, 203 (45\%) of the employees work in the dry cargo market and 39 (8.6\%) work in the Ro-Ro market in the ship business with an average year of activity of 12.4 years.

\subsection{Measures}

The validity and reliability of all measurement tools used to collect data in this study were tested in previous studies, and items in the scale were arranged using the 5-point Likert rating scale ( $1=$ strongly disagree; $5=$ strongly agree).

\subsubsection{KM Scale}

A 20 -item scale (Cronbach's Alpha $>0.70$ ), with dimensions of KT (e.g., "There is a culture that encourages knowledge sharing"), knowledge applications (e.g., "To benefit from knowledge resources, information is transferred to application areas"), knowledge creating (e.g., "I can generate new knowledge from existing business data"), and knowledge storing (e.g., "I systematically store the knowledge necessary for the job"), was used as a KM scale. The scale, originally developed by Lee et al. [54], was adapted to Turkish and tested for validity and reliability by Çetinkaya [55]. Since the four items were idle or loaded to more than one dimension in the explanatory factor analysis (EFA) that was carried out using the principal components analysis and the Varimax rotation technique to determine the consistency of the scale, these items were removed. Results of the analysis showed that the KM scale has a four-dimensional structure with eigenvalues greater than 1 [Kaiser-Meyer-Olkin (KMO) $=0.833 ; \chi^{2}=2476.660$; $\mathrm{df}=120$; $\mathrm{p}<0.001$; factor loads range from 0.596-0.855; total explained variance: $67.8 \%]$.

\subsubsection{SP Scale}

A two-dimensional, namely NP (e.g., "The voyage planning is done quickly and without errors") and CP (e.g., "Knowledge about the cargo is delivered to the ships on time and quickly"), and eight-item scale (Cronbach's Alpha>0.65) developed by Yorulmaz [33] was used to measure the SP. The EFA, which was performed to determine the consistency of the scale using the principal components analysis and the Varimax rotation technique, showed that the scale has a two-dimensional structure with eigenvalues greater than 1 (KMO=0.768; $\chi^{2}=901.495 ; \mathrm{df}=28 ; \mathrm{p}<0.001$; factor loads range from 0.598-0.827; total explained variance: $62.3 \%$ ).

\subsection{Analysis Methods}

Data obtained through surveys were analyzed using SPSS 22 and AMOS 22 statistical package programs. Discriminant and convergent validities were used to determine the validity of the measurement model, and Cronbach's alpha and composite reliability (CR) coefficients were used to determine the reliability of the measurement model. The structural equation modeling used for path analysis with AMOS 22 and the Bootstrap based on 5000 samples was utilized for the analysis of the moderating role, and the SPSS 22 Hayes (2019) Process macro (v3.4) plugin was used.

\section{Results}

\subsection{Validity and Reliability Analysis}

A confirmatory factor analysis (CFA) was performed to measure the validity and reliability of the measurement model. Results determined that standardized factor loads of the variables observed were greater than 0.50 and statistically significant [standardized $\beta$ : 0.606$0.846 ; \mathrm{p}<0.001]$. However, goodness-of-fit values of the measurement model $\left[\chi^{2} / \mathrm{df}=2,020\right.$; comparative fit index $(\mathrm{CFI})=0.931$; tucker-lewis index $(\mathrm{TLI})=0.917$; root mean square error of approximation (RMSEA) $=0.048$; standardized root mean square residual $(\mathrm{SRMR})=0.025]$ were within acceptable limits $[56,57]$. For the convergent validity of the scales in the measurement model, the average variance extracted (AVE) and CR values were calculated, and the square root values of the AVE were calculated for the discriminant validity. Tables 1-3 show the results.

Evident in Table 1, results confirmed the convergent validity of the measurement model as the AVE values of all factors were greater than the critical value (0.50), and CR values, which exhibited values greater than the threshold value (0.70), were greater than the AVE values $[57,58]$.

Table 2 shows that relationships between all factors were significant $(\mathrm{p}<0.01)$. The divergent validity was confirmed because the AVE square root values were greater than the Pearson correlation coefficients between the factors [57] and also because the correlation coefficients were less than 0.85 [59]. However, Table 1 shows that the measurement tools are reliable [57] scales since the CR and CA values were greater than 0.70 .

Values of CFA fit indices for the path analysis of the measurement model with confirmed validity and reliability are given in Table 3, where the second-order $\mathrm{KM}$ and first order SP CFA were used because the second-order CFA goodness-of-fit values for KM and the first order CFA goodness-of-fit values were more suitable for SP and for the research purposes.

Moreover, since the independent and dependent variables in the measurement tool were responded to by the same respondents at the same time, Harman's single factor test was carried out to determine the common method bias and 
particular attention was paid to the scale order to prevent it. In the first part of the survey, dimensions of the dependent variable SP were included in the SP and CP questions, and questions of the dependent variable KM were included in the second part of the survey to balance the order of the scale. Further, the EFA analysis, conducted with the principal components method and without rotation, yielded factor components with five factors and eigenvalues greater than 1 as well as the explained total variance of $52.2 \%$ with the first factor alone explaining $18.7 \%$ of the total variance. That is, there was more than one-factor structure in the said EFA analysis, and the first factor did not have a significant

Table 1. Convergent validity and Cronbach's Alpha

\begin{tabular}{|c|c|c|c|c|c|c|}
\hline Factors & $\begin{array}{l}\text { Observed } \\
\text { variables }\end{array}$ & $\begin{array}{c}\text { Standardized } \\
\beta\end{array}$ & t-values & AVE & CR & CA \\
\hline \multirow{4}{*}{ NP } & NP1 & 0.846 & $10,526^{* * *}$ & \multirow{4}{*}{0.506} & \multirow{4}{*}{0.801} & \multirow{4}{*}{0.717} \\
\hline & NP2 & 0.606 & $8,460^{* * *}$ & & & \\
\hline & NP3 & 0.741 & $10,013^{* * *}$ & & & \\
\hline & NP4 & 0.626 & - & & & \\
\hline \multirow{4}{*}{$\mathrm{CP}$} & $\mathrm{CP} 1$ & 0.666 & $9,987^{* * *}$ & \multirow{4}{*}{0.522} & \multirow{4}{*}{0.814} & \multirow{4}{*}{0.740} \\
\hline & $\mathrm{CP} 2$ & 0.737 & $10,217^{* * *}$ & & & \\
\hline & $\mathrm{CP} 3$ & 0.749 & $10,876^{* * *}$ & & & \\
\hline & $\mathrm{CP} 4$ & 0.736 & - & & & \\
\hline \multirow{5}{*}{ KT } & KT1 & 0.662 & $9,910^{* * *}$ & \multirow{5}{*}{0.518} & \multirow{5}{*}{0.843} & \multirow{5}{*}{0.813} \\
\hline & KT2 & 0.748 & $12,478^{* * *}$ & & & \\
\hline & KT3 & 0.741 & $12,404^{* * *}$ & & & \\
\hline & KT4 & 0.682 & $11,128^{* * *}$ & & & \\
\hline & KT5 & 0.761 & - & & & \\
\hline \multirow{4}{*}{ KA } & KA1 & 0.773 & $13,689^{* * *}$ & \multirow{4}{*}{0.525} & \multirow{4}{*}{0.792} & \multirow{4}{*}{$0.77 €$} \\
\hline & KA2 & 0.712 & $13,004^{* * *}$ & & & \\
\hline & KA3 & 0.689 & $10,899^{* * *}$ & & & \\
\hline & KA4 & 0.721 & - & & & \\
\hline \multirow{4}{*}{ KC } & KC1 & 0.738 & $11,416^{* * *}$ & \multirow{4}{*}{0.518} & \multirow{4}{*}{0.811} & \multirow{4}{*}{0.759} \\
\hline & KC2 & 0.688 & $10,552^{* * *}$ & & & \\
\hline & KC3 & 0.777 & $11,772 * * *$ & & & \\
\hline & KC4 & 0.670 & - & & & \\
\hline \multirow{3}{*}{ KS } & KS1 & 0.775 & $9,188^{* * *}$ & \multirow{3}{*}{0.636} & \multirow{3}{*}{0.840} & \multirow{3}{*}{0.742} \\
\hline & KS2 & 0.784 & $9,876^{* * *}$ & & & \\
\hline & KS3 & 0.832 & $10,243^{* * *}$ & & & \\
\hline
\end{tabular}

AVE: Average variance extracted, CR: Composite reliability, CA: Cronbach's Alpha, NP: Navigational performance, CP: Cargo performance, KT: Knowledge transfer, KA: Knowledge applications, KC: Knowledge creating, KS: Knowledge storing

Table 2. Pearson correlation and square root of AVE

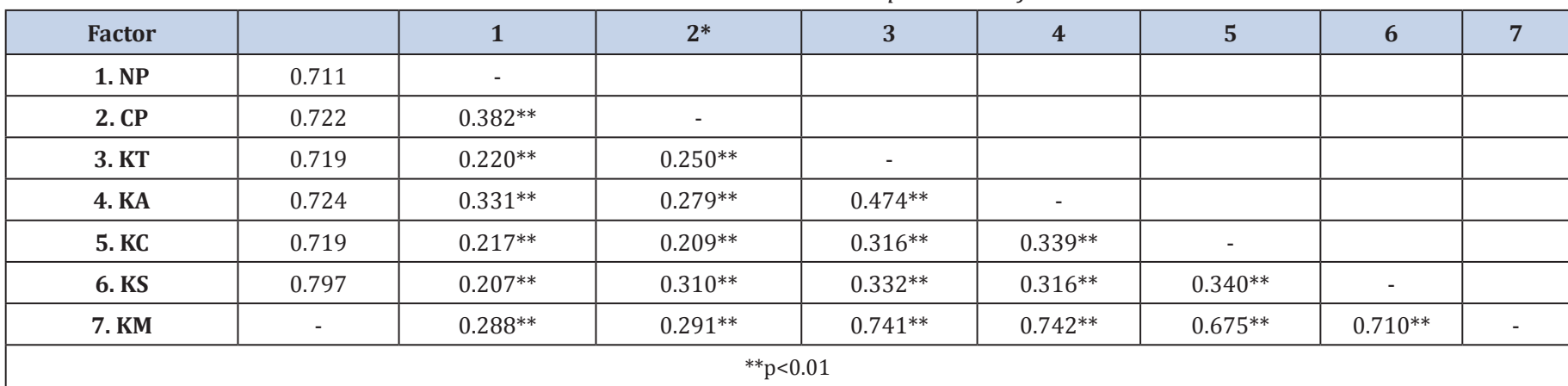

AVE: Average variance extracted, NP: Navigational performance, CP: Cargo performance, KT: Knowledge transfer KM: Knowledge management, KA: Knowledge applications, KC: Knowledge creating, KS: Knowledge storing 
explanation in the total explained variance. Lastly, the CFA analysis, where all observed variables were handled with a single factor, was conducted. It can be argued that no common method variance bias occurred because the CFA of the single factor model $\left(\chi^{2} / \mathrm{df}=8,120 ; \mathrm{CFI}=0.473\right.$; TLI $=0.423$; RMSEA=0.126; SRMR=0.054) was far below the acceptable limits [60,61].

Prior to testing the research hypotheses, skewness, and kurtosis coefficients of the factors were calculated and variables were examined to see whether they had a normal distribution. Results and averages of the factors are given in Table 4 where the data showed a normal distribution [59], since the skewness coefficients were between -0.765 and -1.090 , the kurtosis coefficients were between 0.316 and 2,404 and less than 3 , and the critical values were less than 10.

\subsection{Testing Hypotheses}

Goodness-of-fit values of the path analysis $\left(\chi^{2} / \mathrm{df}: 2,157\right.$; CFI: 0.919; TLI: 0.906; RMSEA: 0.051; SRMR $=0.031$ ) were within the acceptable limits $[56,57]$ and were found by the structural equation modeling shown schematically in Figure 2 to reveal the impact of KM applications on the ship performance in ship operations. Results of the path analysis demonstrated that KM applications had a significant and positive effect on NP (std. $\beta$ : $0.410 ; t: 5,008 ; p<0.001$ ) and that KM explained approximately $17 \%$ of the change in NP $\left(R^{2}: 16.9\right)$. Based on these findings, Hypothesis 1 was accepted. Likewise, KM applications had a significant and positive effect on CP (std. $\beta$ : 0.360; t: 4,026; $p<0.001$ ), and
KM explained about $13 \%$ of the change in $C P\left(R^{2}: 13.1\right)$. Based on these findings, Hypothesis 2 was accepted.

The SPSS 22 Hayes [62] Process macro (v3.4) plugin was used to examine whether the BOP has a moderating effect in the relationship between the KM applications and the ship's NP and CP in ship businesses. Table 5 presents the results

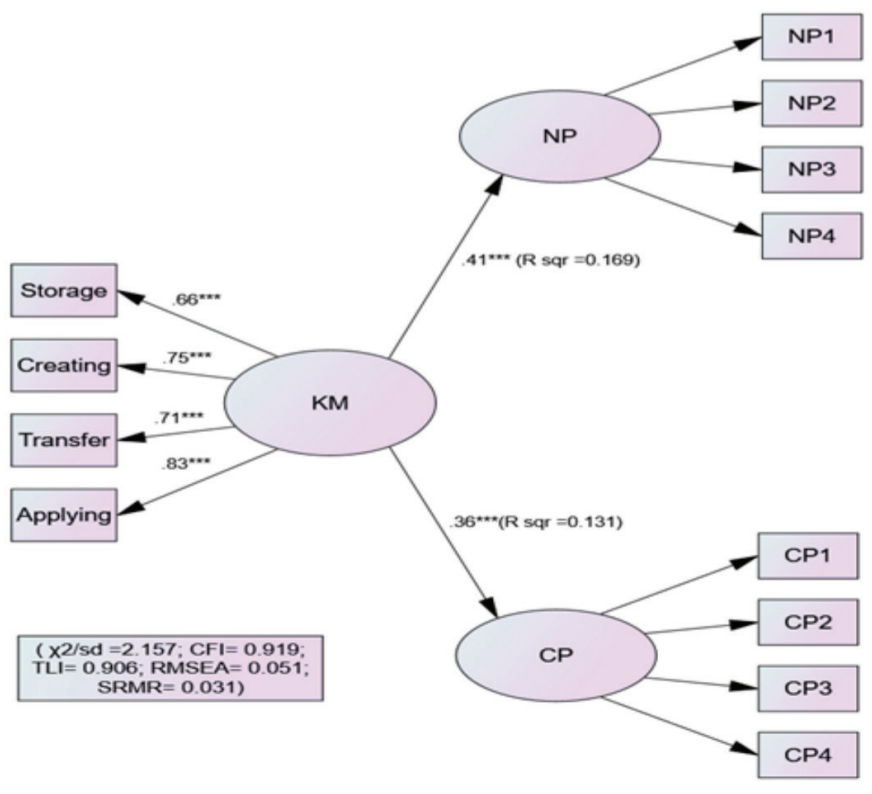

Figure 2. Path analysis

NP: Navigational performance, CP: Cargo performance, KM: Knowledge management, CFI: Comparative fit index, RMSEA: Root mean square error of approximation, SRMR: Standardized root mean square residual, TLI: Tucker-lewis index

Table 3. Confirmatory factor analysis goodness-of-fit indices

\begin{tabular}{|c|c|c|c|c|c|c|c|}
\hline Scales & $\chi^{2}$ & df & $\chi^{2} / \mathbf{d f}$ & CFI & TLI & RMSEA & SRMR \\
\hline First order KM & 227,335 & 95 & 2,393 & 0.943 & 0.930 & 0.056 & 0.026 \\
\hline Second order KM & 226,881 & 97 & 2,339 & 0.947 & 0.933 & 0.055 & 0.025 \\
\hline First order SP & 32,758 & 16 & 2,047 & 0.981 & 0.967 & 0.048 & 0.017 \\
\hline Second order SP & 80,129 & 17 & 4,713 & 0.928 & 0.882 & 0.091 & 0.025 \\
\hline
\end{tabular}

Table 4. Means, standard deviations, skewness, and kurtosis

\begin{tabular}{|c|c|c|c|c|c|c|}
\hline Factors & Means & SD & Skewness & SE & Kurtosis & SE \\
\hline 1. NP & 3,726 & 0.491 & -0.881 & 0.115 & 1,139 & 0.229 \\
\hline 2. $\mathrm{CP}$ & 3,688 & 0.509 & -0.890 & 0.115 & 1,691 & 0.229 \\
\hline 3. KT & 3,898 & 0.544 & -0.808 & 0.115 & 0.708 & 0.229 \\
\hline 4. KA & 3,929 & 0.543 & -0.868 & 0.115 & 0.721 & 0.229 \\
\hline 5. KC & 3,968 & 0.496 & -0.765 & 0.115 & 0.316 & 0.229 \\
\hline 6. KS & 3,855 & 0.583 & $-1,090$ & 0.115 & 2,404 & 0.229 \\
\hline 7. KM & 3,913 & 0.388 & -0.801 & 0.115 & 1,215 & 0.229 \\
\hline
\end{tabular}


Table 5. Moderating effect test of NP and CP

\begin{tabular}{|c|c|c|c|c|c|c|}
\hline Variables & B & SE & $\mathbf{t}$ & $\mathbf{p}$ & \multicolumn{2}{|c|}{$\begin{array}{c}\text { 95\% CI } \\
\text { LL UL }\end{array}$} \\
\hline (NP) Constant & 4,477 & 0.022 & 200,205 & 0.000 & 4,383 & 4,470 \\
\hline KM & 0.370 & 0.057 & 6,505 & 0.000 & 0.258 & 0.482 \\
\hline BOP & 0.006 & 0.017 & 0.347 & 0.728 & -0.028 & 0.040 \\
\hline KM*BOP & 0.059 & 0.045 & 1.301 & 0.193 & -0.030 & 0.148 \\
\hline Model 1 Sum. & \multicolumn{6}{|c|}{$\mathrm{R}^{2}=0.093 ; \mathrm{F}=15,364 ; \mathrm{p}<0.001 ; \Delta \mathrm{R}^{2}=0.003$} \\
\hline (CP) Constant & 4,387 & 0.023 & 186,083 & 0.000 & 4,341 & 4,433 \\
\hline KM & 0.256 & 0.060 & 4,224 & 0.000 & 0.137 & 0.376 \\
\hline BOP & 0.019 & 0.018 & 1,040 & 0.298 & -0.017 & 0.056 \\
\hline KM*BOP & 0.024 & 0.048 & 0.513 & 0.607 & 0.119 & 0.070 \\
\hline Model 2 Sum. & \multicolumn{6}{|c|}{$\mathrm{R}^{2}=0.040 ; \mathrm{F}=6,215 ; \mathrm{p}<0.001 ; \Delta \mathrm{R}^{2}=0.0006$} \\
\hline
\end{tabular}

of the moderating test performed by applying the Bootstrap 5000 resampling technique.

It is noted in Table 5 that models tested with the moderating effect analysis were statistically significant (Model $1 \mathrm{R}^{2}=0.093 ; \mathrm{F}=15,364 ; \mathrm{p}<0.001$ ) (Model $2 \mathrm{R}^{2}=0.093$; $F=15,364 ; p<0.001)$, but the effect of the interaction term $\left(\mathrm{KM}^{*} \mathrm{BOP}\right)$ on both NP $(\mathrm{B}=0.059 ; \mathrm{t}=1.301 ; \mathrm{p}>0.05)$ and $\mathrm{CP}$ $(B=0.024 ; t=-0.513 ; p>0.05)$ was not statistically significant. The fact that the interaction term was not statistically significant indicated that the BOP had no moderating effect on the relationship between the KM applications and the ship's NP and CP. Based on these findings, Hypothesis 3 and Hypothesis 4 were rejected.

\section{Discussion}

To determine the effect of KM applications in the ship management on the NP and CP of ships and whether the BOP has a moderating effect in this interaction, data were drawn from surveys with 451 employees of 67 ship managements in Turkey, which were then analyzed using SPSS 22 Hayes [62] Process macro (v3.4) and AMOS 22 programs. Results of the path analysis based on the structural equation modeling showed that the KM applied in ship managements both on NP (std. $\beta$ : $0.410 ;$ t: 5,$008 ; p<0.001$ ) and on CP (std. $\beta$ : 0.360; $t: 4,026 ; p<0.001)$ had a significant and positive effect. This study also ascertained that the KM explained approximately $17 \%$ of the change in NP $\left(\mathrm{R}^{2}: 16.9\right)$ and approximately $13 \%$ of the change in CP $\left(\mathrm{R}^{2}: 13.1\right)$. Based on these findings, Hypothesis 1 and Hypothesis 2 were accepted.

These findings are congruent with studies in different sectors that pointed out the positive impact of $\mathrm{KM}$ on performance [44-49]. The knowledge available for use in sea transportation with a multidisciplinary structure, which operates $24 / 7$, typically includes implicit information that seafarers have. The varying nature of factors to be encountered during the voyage period affects the performance of the ship. Thus, the variable implicit and explicit information on conditions such as cargo, port characteristics, weather conditions in the port, unknown information on sea and weather conditions during the voyage period, currents, and conditions related to the port of arrival, and traffic density play a decisive role in the performance of the ship. With the extending reach of information technologies and the adaptation of innovations to ships, the knowledge flow between ships and the second and third institutions such as the operation, receiver, charterer, and agency has accelerated, been diversified, and strengthened. Therefore, it has become easier for ship managers (Master, Chief Officer, Chief Engineer, $2^{\text {nd }}$ Engineer, etc.) equipped with specific knowledge to access and transform the knowledge outside their implicit and explicit knowledge. While KM applications for $\mathrm{CP}$ are applied without any change (cargo stowage, steps, working hours, etc.) between ship managers and second parties in line with fixed information such as cargo properties and requirements, port properties, and requirements, KM applications may be more effective for $\mathrm{NP}$, since situations such as alternative route determination, speed adjustment, and up-to-date information about the port to be visited entail more information flow and further interpretation, considering factors such as current, traffic density, and security of the region to which the navigation is made, especially for weather conditions for NP. Ship managements can increase their NP by directly supporting the ship (route recommendation, weather, regional and seasonal current information, etc.). Further, NP may have an indirect effect on $\mathrm{CP}$, since there may be problems with the cargo in cases such as the possibility of the ship being exposed to heavy seas during navigation. 
The SPSS 22 Hayes [62] Process macro (v3.4) plugin was used to examine whether the BOP has a moderating effect in the relationship between KM applications and ship performance in ship managements. Results of the moderating effect analysis performed using the Bootstrap 5000 sampling technique showed that the BOP lacked a moderating effect in the relationship between the KM and both NP and CP. According to these findings, Hypothesis 3 and Hypothesis 4 were rejected. This finding is congruent with the study by Karaman and Kale [52]. Based on these findings, KM applications in ship managements positively support the NP and CP of ships, regardless of the BOP.

\section{Limitations and Suggestions}

This study presents some limitations. First, the data were obtained from shipping companies operating in Turkey. Therefore, the findings are limited to this sample. In addition, this study did not consider the differences in the activity fields of shipping companies, i.e., shipping companies operating in the container sector, tanker sector, or dry cargo sector were evaluated together. However, it is known that KM applications and ship performances may differ depending on the activity fields of the shipping companies. Therefore, further research may consider the relationship between the KM and ship performance in shipping firms individually for each sector. Further, different variables can be added to the research model and in-depth studies can be performed to improve this model.

\section{Conclusion}

To prevent disputes that may occur in maritime transportation, which is at the center of international trade, countries become a party to various agreements and contracts prepared by international organizations on issues such as safety, security, and environmental protection. Commercial ships that do not comply with such agreements and contracts may be inspected by competent authorities and detained when deemed necessary. In this context, there is not a major difference between newly established companies and companies established in earlier years, because all benefit from the same knowledge pool to equip and operate their ships. The main reason for the lack of the moderating effect of the BOP in the relationship between the KM applications and ship performance in ship managements is that all ship managements that want to operate in the maritime sector ensure the safety of life and property in their ships by following processes in line with principles of the international safety management. Therefore, companies have the chance to instantly acquire the knowledge that a company can gain through years of experience. Due to the nature of work done in maritime management and merchant ships, the working period on ships is rather short. Since precious and distinctive knowledge is the implicit knowledge of employees, taking some measures to ensure that these employees stay in the company is important for both ship and firm performances. It is much more substantial for sea transportation that employees are confident, well equipped, and know what they are doing, because even a slight hesitation may cause serious consequences such as environmental pollution and loss of life and property at sea. Thus, business executives can regularly gather their employees and create an environment where they can exchange their knowledge, which also increases the value of human resources and supports the spread of existing knowledge among employees. They can enable their employees to take part in vocational courses and seminars and organize activities in collaboration with educational units of universities, especially for officers at the management level. Further, a training and development department can be established within the management company, so knowledge can be available as a tangible resource within the company and can be applied immediately when requested. This will also increase the prestige of the maritime company for its employees. Moreover, they perform regular and annual work on the effects of the KM applications on the ship and share their findings with the company and the ships under their possession, emphasizing the importance of these applications and encouraging employees in regard to these applications.

\section{Authorship Contributions}

Concept design: M. Yorulmaz, Data Collection or Processing: M. Yorulmaz, A. Karabacak, Analysis or Interpretation: M. Yorulmaz, Literature Review: M. Yorulmaz, A. Karabacak, Writing and Reviewing: M. Yorulmaz, A. Karabacak, Editing: M. Yorulmaz.

Funding: The author(s) received no financial support for the research, authorship, and/or publication of this article.

\section{References}

[1] S. H. Liao, and C. C. Wu, "The relationship among knowledge management, organizational learning, and organizational performance." International Journal of Business and Management, vol. 4, pp. 64-76, April 2009.

[2] P. Quintas, P. Lefrere, and G. Jones, "Knowledge management: A strategic agenda." Long Range Planning, vol. 30, pp. 385-391, Jun 1997.

[3] C. L.-H. Chang, and T.-C. Lin, "The role of organizational culture in the knowledge management process." Journal of Knowledge Management, vol. 19, pp. 433-455, 2015.

[4] M. Yorulmaz, "Denizcilik işletmelerinde örgütsel yapı ve bilginin uygulama süreci arasındaki ilișkilerin incelenmesi." Uluslararası Yönetim Araştırmaları Dergisi, vol. 2, pp. 190-198, Jan 2016. 
[5] M. Alavi, and D. E. Leidner, "Review: knowledge management and knowledge management systems: Conceptual foundations and research issues." Misquarterly Review, vol. 25, pp. 107-136, Mar 2001.

[6] T. Almeida, J. B. Vasconcelos, and G. Pestana, "A knowledge management architecture for information technology services delivery." $201813^{\text {th }}$ Iberian Conference on Information Systems and Technologies (CISTI) Caceres, (s. 1-4). Lisboa, Portugal.

[7] UNCTAD (United Nations Conference on Trade and Development). Review of Maritime Transport. New York, 2019.

[8] E. S. Lee, and D. W. Song, "Knowledge management for maritime logistics value: Discussing conceptual issues.” Maritime Policy Management, vol. 37, pp. 563-583, Oct 2010.

[9] T. Andreeva, and A. Kianto, "Does knowledge management really matter? Linking knowledge management practices, competitiveness and economic performance." Journal of Knowledge Management, vol. 16, pp. 617-636, Jul 2012.

[10] J. Darroch. "Knowledge Management, innovation and firm performance." Journal of Knowledge Management, vol. 9, pp. 101-115, Jun 2005.

[11] B. Choi, S. K. Poon, and J. G. Davis, "Effects of knowledge management strategy on organizational performance: A complementarity theory-based approach." Omega The International Journal of Management Science, vol. 36, pp. 235-251, April 2008.

[12] R. Payal, S. Ahmed, and R. M. Debnath, "Impact of knowledge management on organizational performance an application of structural equation modeling." VINE Journal of Information and Knowledge Management Systems, vol. 49, pp. 510-530, Oct 2019.

[13] F. Rezaei, H. Hosseinzadeh, and A. Dehghan, "Investigating the effect of knowledge management dimensions on the level of performance of nurses working in ayatollah Rouhani Hospital in Babol," World Family Medicine/Middle East Journal of Family Medicine, vol. 16, pp. 231-236, Mar 2018.

[14] A. Özdemir, Yönetim Biliminde İleri Araştırma Yöntemi ve Uygulamalar. İstanbul: Beta Basım Yayım Dağıtım A.Ş., 2013.

[15] M. Deja, and D. Rak, "Knowledge management and academic information behaviour a preliminary study of metaliteracy among junior faculty staff in the digital environment." Aslib Journal of Information Management, vol. 71, pp. 480-499, May 2019.

[16] P. M. Norman, "Knowledge acquisition, knowledge loss, and satisfaction in high technology alliances." Journal of Business Research, vol. 57, pp. 610-619, Jun 2004.

[17] H. Shihabeldeen, N. Babiker, and N. Ahmed, "Tacit knowledge sharing: The role of individual factors." Management Science Letters, vol. 10, pp. 2343-2350, Feb 2020.

[18] M. M. Ajmal, and K. U. Koskinen, "Knowledge transfer in project-based organizations: An organizational culture perspective." Project Management Journal, vol. 39, pp. 7-15, Mar 2008.

[19] I. Nonaka, R. Toyama, and N. Konno, "SECI, Ba and leadership: a unified model of dynamic knowledge creation." Long Range Planning, vol. 33, pp. 5-34, Feb 2000.

[20] U. Lichtenthaler, "Relative Capacity: Retaining knowledge outside a firm's." Journal of Engineering and Technology Management, vol. 25, pp. 200-212, Sep 2008.
[21] A. Cabrera, and E. F. Cabrera, "Knowledge-sharing dilemmas." Organization Studies, vol. 25, pp. 687-710, Sep 2002.

[22] M. Ipe, "Knowledge sharing in organizations: A conceptual framework." Human Resource Development Review, vol. 2, pp. 337-359, Dec 2003.

[23] P. Hendriks, "Why share knowledge? The influence of ICT on the motivation for knowledge sharing." Knowledge and Process Management, vol. 6, pp. 91-100, Jun 1999.

[24] M. Mahmoudsalehi, R. Moradkhannejad, and K. Safari, "How knowledge management is affected by organizational structure," The Learning Organization, vol. 19, pp. 518-528, Sep 2012.

[25] M. Dubnick, "Accountability and the promise of performance: In search of the mechanisms." Public Performance \& Management Review, vol. 28, pp. 376-417, Mar 2005.

[26] W. V. Dooren, G. Bouckaert, and J. Halligan, Performance Management in the Public Sector. $2^{\text {nd }}$ Ed. London \& New York: Routledge, 2015.

[27] D. S. Elenkov, "Effects of leadership on organizational performance in Russian companies." Journal of Business Research, vol. 55, pp. 467-480, Jun 2002.

[28] J. G. March, and R. I. Sutton, "Organizational performance as a dependent variable." Organization Science, vol. 8, pp. 698-706, Dec 1997.

[29] I. Y. Abu-Jarad, N. Yusof, and D. Nikbin, "A review paper on organizational culture and organizational performance." International Journal of Business and Social Science, vol. 1, pp. 26-46, Dec 2010.

[30] S. Kim, "Individual-level factors and organizational performance in government organizations." Journal of Public Administration Research and Theory, vol. 15, pp. 245-261, Dec 2004.

[31] R. Lu, O. Turan, E. Boulougouris, C. Banks, and A. Incecik, "A semi-empirical ship operational performance prediction model for voyage optimization towards energy efficient shipping." Ocean Engineering, vol. 110, pp. 18-28, Dec 2015.

[32] P. B. Pjedsted, "Data-driven Vessel Performance Monitoring." Danimarka: DTU Mechanical Engineering. DCAMM Special Report, No. S180, 2014.

[33] M. Yorulmaz, "Çalışan algısına göre gemi performansı ölçeğinin geliştirilmesi: geçerlilik ve güvenilirlik çalışması." Avrasya Uluslararası Araştırmalar Dergisi, vol. 7, pp. 1053-1065, Mar 2019.

[34] C. Searcy, S. Karapetrovic, and D. McCartney, "Application of a systems approach to sustainable development performance measurement." International Journal of Productivity and Performance Management, vol. 57, pp. 182-197, Jan 2008.

[35] R. L. Townsin, and Y. J. Kwon, "Estimating the influence of weather on ship performance." RINA Trans, vol. 135, pp. 191209, Aug 1993.

[36] Y. J. Kwon, "Speed loss due to added resistance in wind and waves." Naval Architect, pp. 14-16, Mar 2008.

[37] K. Sasa, et al. "Evaluation of ship performance in international maritime transportation using an onboard measurement system - in case of a bulk carrier in international voyages." Ocean Engineering, vol. 104, pp. 294-309, Aug 2015.

[38] M. Bentin, D. Zastrau, M. Schlaak, D. Freye, R. Elsner, and S. Kotzur, "A new routing optimization tool-influence of wind and waves 
on fuel consumption of ships with and without wind assisted ship propulsion systems." Transportation Research Procedia, vol. 14, pp. 153-162, Dec 2016.

[39] P. Deligiannis, "Ship performance indicator." Marine Policy, vol. 75, pp. 204-209, Jan 2017.

[40] P. A. Lakshmynarayanana, and D. A. Hudson, "Is wave height necessary to determine ship performance in calm water from measurements?" in $3^{\text {rd }}$ Hull Performance and Insight Conference, Redworth, Darlington 335-346, Mar 2017.

[41] O. Soner, E. Akyuz, and M. Celik, "Use of tree based methods in ship performance monitoring under operating conditions." Ocean Engineering, vol. 166, pp. 302-310, Aug 2018.

[42] M. Palamut, and D. Ö. Çaylan, "Gemi işletmeciliğinde etkinlik ve performans göstergeleri: Kuru dökme yük deniz taşımacıllğı alanında hizmet sunan gemi sahibi işletmede bir uygulama." Verimlilik Dergisi, vol. 13, pp. 49-83, Jul 2016.

[43] M. Ö. Keleş, and S. Kum, "Türk koster işletmeciliğinde "üçüncü taraf" ve "tam kurum içi" yönetimler arası gemicilik performans endekslerine dayalı karşılaștırma." Journal of ETA Maritime Science, vol. 7, pp. 65-77, Mar 2019.

[44] L. Al-Abbadi, R. Alshawabkeh, and A. Rumman, Knowledge management processes and innovation performance: The moderating effect of employees' knowledge hoarding. Management Science Letters, vol. 10, pp. 1463-1472, 2020.

[45] A. J. Carrasco-Hernández, and D. Jiménez-Jiménez, "Knowledge management, flexibility and firm performance: The effects of family involvement." European Journal of Family Business, vol. 6, pp. 108-117, Jul-Dec 2017.

[46] M. Birasnav, "Knowledge management and organizational performance in the service industry: The role of transformational leadership beyond the effects of transactional leadership." Journal of Business Research, vol. 67, pp. 1622-1629, Aug 2014.

[47] S. Dur, Bilgi Yönetimi Altyapısı ve Bilgi Yönetimi Sürecinin Örgütsel Performans Üzerindeki Etkisi (MSc Thesis). Abant İzzet Baysal Üniversitesi, 2008.

[48] S. A. Ahbabi, S. K. Singh, S. Balasubramanian, and S. S. Gaur, "Employee perception of impact of knowledge management processes on public sector performance." Journal of Knowledge Management, vol. 23, pp. 351-373, Apr 2019.

[49] N. Jain, and V. Gupta, "The impact of knowledge management system on student performance a case study of the University of Delhi." VINE Journal of Information and Knowledge Management System, vol. 49, pp. 115-135, Feb 2019.
[50] E. S. Lee, and D. W. Song, "Knowledge management in freight forwarding as a logistics intermediator: Model and effectiveness." Knowledge Management Research \& Practice, vol. 16, pp. 488-497, May 2018.

[51] C.-C. Yang, P. B. Marlow, and C.-S. Lu, "Knowledge management enablers in liner shipping." Transportation Research Part E, vol. 45, pp. 893-903, Nov 2009.

[52] A. E. Karaman, and S. Kale, "Bilgi yönetimi sağlayıcıları ve inşaat firmalarının performansı.” BAÜ FBE Dergisi, vol. 11, pp. 28-41, Jun 2009.

[53] D. Türk, F. Aygen, and S. Yıldız, "Muhasebe departmanlarında bilgi yönetimi." Muhasebe ve Finansman Dergisi, vol. 44, pp. 236250, Oct 2009.

[54] K. C. Lee, S. Lee, and I. W. Kang, "KMPI: Measuring knowledge management performance." Information \& Management, vol. 42, pp. 469-482, Mar 2005.

[55] A. Çetinkaya, "Örgütsel bilgi yönetim sürecinde bilgi yönetim performansı boyutları: Ölçek geliştirme ve geçerliliği üzerine bir araştırma." Öneri Dergisi, vol. 10, pp. 157-162, Oct 2012.

[56] L. Hu, and P. M. Bentler, "Cut off criteria for fit indexes in covariance structure analysis: Conventional criteria versus new alternatives." Structural Equation Modeling: A Multidisciplinary Journal, vol. 6, pp. 1-55, Nov 2009.

[57] J. F. Hair, W. C. Black, B. J. Babin, R. E. Anderson, Multivariate Data Analysis. $7^{\text {th }}$ ed. New Jersey: Prentice Hall, UK, 2014.

[58] C. Fornell, and D. F. Larcker. "Evaluating structural equation models with unobservable variables and measurement error." Journal of Marketing Research, vol. 18, pp. 39-50, Feb 1981.

[59] R. B. Kline, "Principles and practice of structural equation modeling." ${ }^{\text {th }}$ ed. London: The Guilford Publications, 2016.

[60] P. M. Podsakoff, S. B. MacKenzie, J. Y. Lee, and N. P. Podsakoff, "Common method biases in behavioural research: A critical review of the literature and recommended remedies." Journal of Applied Psychology, vol. 88, pp. 879, Oct 2003.

[61] P. M. Podsakoff, S. B. MacKenzie, and N. P. Podsakoff, "Sources of method bias in social science research and recommendations on how to control it," Annual Review of Psychology, vol. 63, pp. 539569, Jan 2012.

[62] A. F. Hayes, Introduction to Mediation, Moderation, and Conditional Process Analysis: A Regression-Based Approach. $2^{\text {nd }}$ ed. New York: Guilford Publications, 2019. 